\title{
Three-Dimensional Radiative Bioconvective Flow of a Sisko Nanofluid with Motile Microorganisms
}

\author{
Hu Ge-JiLe ${ }^{1}$, Hassan Waqas ${ }^{2}$ (), Sami Ullah Khan ${ }^{3}$, Muhammad Ijaz Khan ${ }^{4, * \mathbb{C}}$, Shahid Farooq ${ }^{4}$ \\ and Sajjad Hussain ${ }^{2}$ \\ 1 School of Science, Huzhou University, Huzhou 313000, China; hugejile21@126.com \\ 2 Department of Mathematics, Layyah Campus, Government College University Faisalabad, \\ Layyah 31200, Pakistan; hassanwaqas22@gcuf.edu.pk (H.W.); hussain.sajjad@gpgcl.giccl.edu.pk (S.H.) \\ 3 Department of Mathematics, COMSATS University Islamabad, Sahiwal 57000, Pakistan; \\ samikhan@cuisahiwal.edu.pk \\ 4 Department of Mathematics and Statistics, Riphah International University I-14, Islamabad 44000, Pakistan; \\ shahid786.ktk@gmail.com \\ * Correspondence: mikhan@math.qau.edu.pk
}

Citation: Ge-JiLe, H.; Waqas, H.; Khan, S.U.; Khan, M.I.; Farooq, S.; Hussain, S. Three-Dimensional Radiative Bioconvective Flow of a Sisko Nanofluid with Motile Microorganisms. Coatings 2021, 11, 335. https://doi.org/10.3390/ coatings11030335

Received: 4 February 2021

Accepted: 5 March 2021

Published: 15 March 2021

Publisher's Note: MDPI stays neutra with regard to jurisdictional claims in published maps and institutional affiliations.

Copyright: (c) 2021 by the authors. Licensee MDPI, Basel, Switzerland. This article is an open access article distributed under the terms and conditions of the Creative Commons Attribution (CC BY) license (https:// creativecommons.org/licenses/by/ $4.0 /)$.

\begin{abstract}
The progressive and enhanced thermal mechanisms of nanoparticles has motivated researchers to give attention to this topic in recent years. The synthesizing and versatile applications of such materials include cooling and heating controlling processes, solar systems, energy production, nanoelectronics, hybrid-powered motors, cancer treatments, and renewable energy systems. Moreover, the bioconvection of nanofluids allows for some motivating applications in this era of bioengineering and biotechnology, such as biofuels, biosensors, and enzymes. With these interesting motivations and applications, this study elucidated upon the three-dimensional bioconvection flow of a Sisko fluid (base fluid) in the presence of a nanofluid over a stretched surface. The additional thermal features of radiation were also incorporated to modify the analysis. The rheological features of shear thinning and shear thickening that are associated with the Sisko nanofluid were comprehensively studied. The problem was formulated using highly nonlinear and coupled differential equations, which were numerically simulated via a shooting scheme. The salient physical applications of flow parameters were graphically underlined in view of shear-thinning and shear-thickening scenarios. The results showed that a decrease in velocity in the presence of buoyancy ratio forces was more conducive to the shear-thinning phenomenon. The increase in temperature profile due the thermal Biot number and surface heating source parameter seemed to be more inflated in the shear-thinning scenario. A lower motile microorganism profile was noted for the bioconvection Lewis number.
\end{abstract}

Keywords: Sisko nanofluid; gyrotactic microorganisms; thermal radiative flux

\section{Introduction}

The enhancement in the thermal efficiency of innumerable materials has drawn scientists' attention due to these materials' applications in engineering and industrial development. The improvement in materials with a low heat transportation rate (ethylene glycol, water) is necessary for engineering and industrial processes, where base liquids gain importance as an energy source. Nanofluids are used to enhance the proficiency of ordinary convectional heat transfer fluids, which are consistent mixtures of a stable fluid. In vehicles, nanofluids are also used as a coolant to improve the efficiency of the heat exchanger/aeration and cooling systems. Nanofluids are widely used in automobile and industrial cooling, cancer treatments, identification, new sources of petrol, microelectronics cooling, cross-breeding motors, home heating/cooling equipment, and so on. Choi [1] used the term nanomaterials for the first time, bearing in mind the overall aim of increasing the heat conductivity of nanofluids. Buongiorno [2] established a theoretical non-homogeneous 
equilibrium theory for the molecular diffusion of nanofluids. Thermophoresis and Brownian motion are considered important tools for evaluating the slip of nanoparticles. Iqbal et al. [3] examined the impact of convection on a Sisko fluid with peristaltic movement in an asymmetrical tube. Ali et al. [4] studied the physical importance of chemical reactions and the Lorentzian intensity aspects of Sisko fluid flows in a curved structure. Chaudhuri and Rathore [5] reviewed an observational analysis of the pressure-driven flow and the temperature distribution of a Sisko fluid flowing across parallel plates with viscous dissipation. Nabil and Mostapha [6] investigated the Hall current and Joule heating effects of a peristaltic flow of a Sisko fluid with moderate stenosis via a porous medium in the tapered artery with slip and convective process parameters. Toghraie et al. [7] analyzed blood flow within various arteries using a non-Newtonian Sisko model for use in bioengineering. Agoor et al. [8] investigated peristaltic flow with heat transfer to a Sisko fluid in ciliated arteries. Ferdows et al. [9] examined the interaction of two-dimensional microorganisms with the movement of mixed convection nanoparticles past elongated sheets. Gangadhar et al. [10] studied aspects of an unsteady free convective nanofluid boundary layer flow over a stretch sheet using a spectral relaxation technique. Jawad et al. [11] analyzed the entropy production and mass generation in the unsteady spinning magnetohydrodynamics (MHD) of aqueous nanotube structures with thermal radiation and entropy generation impacts. Ali et al. [12] investigated the core features of the mechanical field of a nanofluid expansion cylinder. Nisar et al. [13] examined the physical elaboration of an Eyring-Powell nanofluid under the effect of activation energy. Muhammad et al. [14] researched the significance of mixed convection in a 3D Eyring-Powell nanoliquid flow using activation energy. Muhammad et al. [15] studied the importance of melting temperature variations in a pressurized base fluid (water), non-liquid (carbon nanotubes (CNTs)+water), and hybrid nanofluid $(\mathrm{CNTs}+\mathrm{CuO}+$ water) flows.

The analysis of non-Newtonian materials is another captivating research area because of their multidisciplinary characteristics and complicated nature. Many biological liquids (including blood), polymer solutions, liquid crystals, solutions, and lubricating oils provide examples of non-Newtonian behavior. The rheological features of such materials cannot be characterized by employing the Newtonian model. A literature survey indicated that various types of non-Newtonian models have been suggested by researchers in order to specify the complicated nature of such materials. The Sisko fluid model is the most modified model, which involves a combination of viscous and power-law models. The Sisko fluid model successfully predicts the interesting features of shear thickening and shear thinning. Various physical properties of viscous and viscoelastic materials are effectively predicted by adjusting the various parameters that are used in this model [16-20].

The bioconvection phenomenon is based on the convection of various materials at the microscopic level. The process of bioconvection is dynamically associated with the fluctuation in the density gradient of the swimming motile microorganisms. It is commonly noticed that microorganisms swim near the upper portion of the surface. The phenomenon of bioconvection is considered an impulsive motion of unicellular microbes in liquids, which results in a nonuniform distribution because of the associated densities of the fluid molecules. The occurrence of these microorganisms increases the primary density of materials and subsequently instigates a gradient with a floating density, which leads to bioconvection. The major cause of bioconvection is the gradient density of motile microorganisms. This theory has significant potential for applicability. For example, it has been used in biology and medicine for cancer treatments or in microsystems for enzyme biomaterials. In addition, it has recently entered the oil and gas industry, in particular, as a technique for the production of microbial fuel. The bioconvection flow of nanoparticles is important for biomolecules, building structures, nanofluid processing, transportation processes, etc. Wager [21] and Platt [22] first introduced the idea of bioconvection. Gyrotactic motile microorganisms often swim in the opposite direction to gravity, where the essential fluid is water. The principle of nanoliquid bioconvection was first investigated by Kuznetsov [23]. Zohra et al. [24] analyzed the slip flow of a nanofluid in the presence of 
motile microorganisms that were confined by a rotating disk. Zhang et al. [25] assessed the motion of axially symmetrical stagnation point motions of magnetization rate nanomaterials that were designed with a porous extended rotating disc in the absence of motile gyrotactic microorganisms. Kotha et al. [26] inspected the two-dimensional hydromagnetic flow and heat transport processes of water-based nanofluids, such as gyrotactic motile microorganisms across a vertical surface through heat generation and absorption. An inviscid, electrically conductive, bioconvective peristaltic fluid flow between two expandable discs was documented by Siddiq et al. [27]. Kumaraswamy et al. [28] measured the effects of heat radiation and partial slipping on the magnetohydrodynamic movement of Jeffrey nanoparticles consisting of motile microorganisms through a vertically spread substrate. Abdelmalek et al. [29] investigated various Arrhenius slip flow relations of thirdgrade nanofluid over a stretching configuration. Waqas et al. [30] recently demonstrated the value of the bioconvection method through the use of nanomaterials and produced significant scientific and industrial applications. Waqas et al. [31] investigated DarcyForchheimer nanofluid bioconvection flowing through the expansion of a cylinder/surface with modified thermal and mass transfer, activation energy, and gyrotactic microorganism characteristics. Wang et al. [32] investigated the active Prandtl features of a bioconvective heat-formed magnetizing tangent hyperbolic nanofluid with gyrotactic motile microorganisms, as well as second-order velocity slipping. Several researchers [33-36] have recently introduced a bioconvective swimming microorganism model to investigate the characteristics of heat transformation.

This paper provides a continuation of the aforementioned research and presents the three-dimensional analysis of the steady and incompressible flow assessment of a Sisko nanofluid accommodating motile microorganisms. The nonlinear thermal radiation relations were imposed to get improve the thermal characteristics of nanofluids. The convective boundary conditions were used to perform the analysis. The novel features of a non-Newtonian Sisko fluid, namely, shear thinning and shear thickening, were observed for all flow parameters. The benchmark conversion of the problem into a dimensionless form by using nonlinear equations, which were numerically solved by using a shooting technique. It is remarked that some theoretical developments already exist in the literature that provide simulations for 3D Sisko nanofluid flows. However, the applications of the bioconvection phenomenon and utilization of nonlinear thermal radiation features have not been reported yet. Therefore, this communication aimed to fill this research gap. A comprehensive physical quantitative analysis was performed for each flow parameter.

\section{Mathematical Modeling}

We assumed a steady flow assessment of a Sisko nanofluid confined by a bidirectional stretched surface. The nanofluid contained motile microorganisms with a uniform density. In an electrically conducting Sisko nanofluid, the magnetic force induction was incorporated along the $z$-direction. The magnitude of the magnetic force was not specified due to the small magnetic Reynolds number assumption. The Brownian and thermophoretic properties of the nanofluid were examined via the Buongiorno model. The mathematical model was developed by using a Cartesian coordinate system, where the velocity components $u$ and $v$ were assumed along the stretching surface, while the zaxis was assumed to be perpendicular to this surface. The surface stretching velocity was denoted with $U_{w}(x)$, while the $V_{w}(y)$ was the stretching velocity along the normal axis, as shown in Figure 1. 


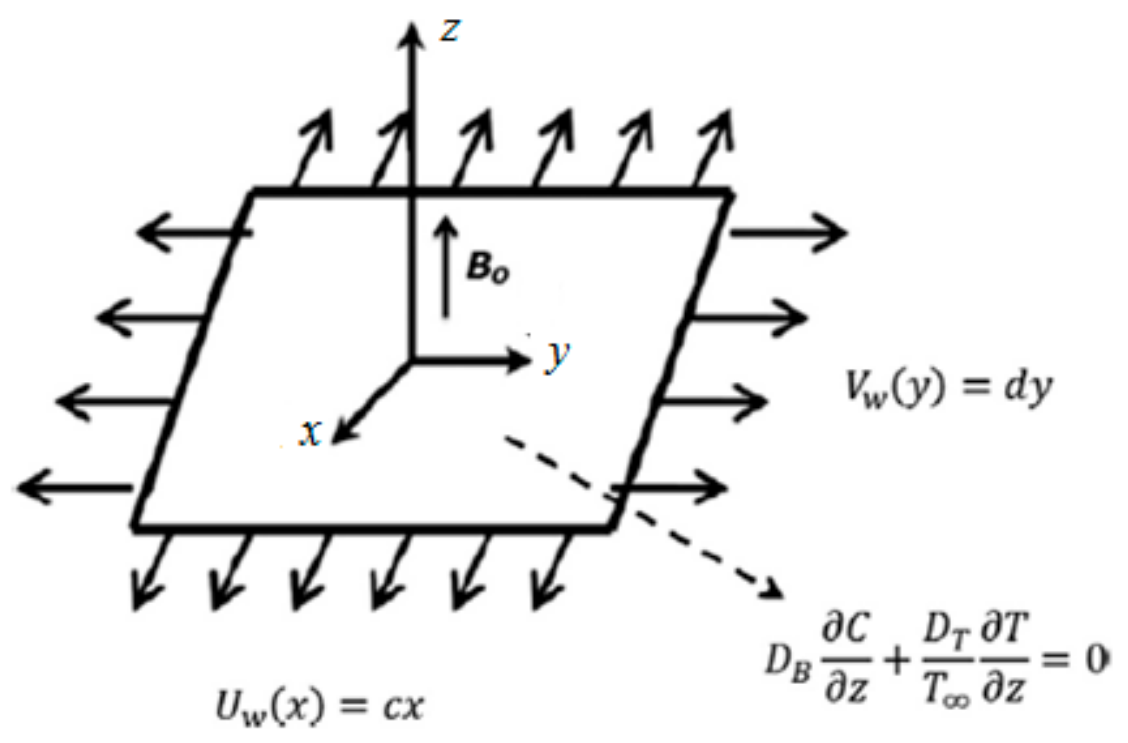

Figure 1. Flow geometry.

The salient features of the thermal radiation were also considered. The governing flow equations of the current flow problem are as follows [16,17]:

$$
\begin{aligned}
& \frac{\partial u}{\partial x}+\frac{\partial v}{\partial y}+\frac{\partial w}{\partial z}=0 \\
& u \frac{\partial u}{\partial x}+v \frac{\partial v}{\partial y}+w \frac{\partial w}{\partial z}=\frac{a}{\rho_{f}} \frac{\partial^{2} u}{\partial z^{2}}-\frac{b}{\rho_{f}} \frac{\partial}{\partial z}\left(-\frac{\partial u}{\partial z}\right)^{n}-\frac{\sigma B_{0}^{2}}{\rho_{f}} u \\
& +\frac{1}{\rho_{f}}\left[\begin{array}{c}
\left(1-C_{\infty}\right) \rho_{f} \beta^{* *} g *\left(T-T_{\infty}\right) \\
-\left(\rho_{p}-\rho_{f}\right) g^{*}\left(C-C_{\infty}\right) \\
-\left(N-N_{\infty}\right) g^{*} \gamma\left(\rho_{m}-\rho_{f}\right)
\end{array}\right], \\
& u \frac{\partial v}{\partial x}+v \frac{\partial v}{\partial y}+w \frac{\partial v}{\partial z}=\frac{a}{\rho_{f}} \frac{\partial^{2} v}{\partial z^{2}}-\frac{b}{\rho_{f}} \frac{\partial}{\partial z}\left(-\frac{\partial u}{\partial z}\right)^{n-1} \frac{\partial v}{\partial z}-\frac{\sigma B_{0}^{2}}{\rho_{f}} v \\
& u \frac{\partial T}{\partial x}+v \frac{\partial T}{\partial y}+w \frac{\partial T}{\partial z}=\alpha_{1} \frac{\partial^{2} T}{\partial z^{2}}+\tau\left(D_{B} \frac{\partial T}{\partial z} \frac{\partial C}{\partial z}+\frac{D_{T}}{T_{\infty}}\left(\frac{\partial T}{\partial z}\right)^{2}\right)-\frac{16 \sigma^{*}}{3(\rho c)_{f} k^{*}} \frac{\partial}{\partial z}\left(T^{3} \frac{\partial T}{\partial z}\right) \\
& u \frac{\partial C}{\partial x}+v \frac{\partial C}{\partial y}+w \frac{\partial C}{\partial z}=D_{B}\left(\frac{\partial^{2} C}{\partial z^{2}}\right)+\frac{D_{T}}{T_{\infty}}\left(\frac{\partial T}{\partial z}\right)^{2} \\
& u \frac{\partial N}{\partial x}+v \frac{\partial N}{\partial y}+w \frac{\partial N}{\partial z}+\left[\frac{\partial}{\partial z}\left(N \frac{\partial C}{\partial z}\right)\right] \frac{b W_{c}}{\left(C_{w}-C_{\infty}\right)}=D_{m} \frac{\partial}{\partial z}\left(\frac{\partial N}{\partial z}\right),
\end{aligned}
$$

with the following boundary assumptions [16,17]:

$$
\begin{gathered}
u=U_{w}(x)=c x, v=V_{w}(y)=d y, w=0, \\
-k \frac{\partial T}{\partial z}=h_{f}\left(T_{w}-T\right), D_{B} \frac{\partial C}{\partial z}+\frac{D_{T}}{T_{\infty}} \frac{\partial T}{\partial z}=0, N=N_{w} \text { at } z=0, \\
u \rightarrow 0, v \rightarrow 0, T \rightarrow T_{\infty}, C \rightarrow C_{\infty}, N \rightarrow N_{\infty} \text { as } z \rightarrow \infty .
\end{gathered}
$$

where $(a, b)$ are the Sisko fluid materials constants, $\rho_{f}$ is the fluid density, $n$ is the behavior index, $\sigma_{1}$ is the electrical conductivity, $B_{0}$ is the magnetic field strength, $\beta^{* *}$ is the volume expansion coefficient, $g$ is the acceleration due to gravity, $v$ is the kinematic viscosity, $T$ is the nanofluid temperature, $\rho_{p}$ is the density of nanoparticles, $\rho_{m}$ is the density of microorganisms, $\tau=(\rho c)_{p} /(\rho c)_{f}$ is the heat capacity ratio, $C$ is the nanofluid concentration, $D_{T}$ is the thermophoresis diffusion coefficient, $D_{B}$ is the diffusion constant, $D_{m}$ is the 
microorganism diffusion constant, $\sigma^{*}$ is the Stefan-Boltzmann constant, $k^{*}$ denotes the mean absorption coefficient, and $\hat{b}$ is the chemotaxis constant.

Suitable variables were used to transform the governing equations into dimensionless form, as follows $[16,17]$ :

$$
\left.\begin{array}{l}
u=c x f^{\prime}(\zeta), v=d y g^{\prime}(\zeta), \\
w=-c\left(\frac{c^{n-2}}{\rho_{f} / b}\right)^{\frac{1}{n+1}}\left[\frac{2 n}{n+1} f+\frac{1-n}{1+n} \zeta f+g\right] x^{\frac{n-1}{n+1}}, \\
\theta(\zeta)=\frac{T-T_{\infty}}{T_{f}-T_{\infty}}, \varphi(\zeta)=\frac{c-C_{\infty}}{C_{\infty}}, \chi(\zeta)=\frac{N-N_{\infty}}{N_{w}-N_{\infty}}, \zeta=z\left(\frac{c^{2-n}}{b / \rho_{f}}\right) x^{\frac{1-n}{1+n}} \cdot
\end{array}\right\}
$$

Applying these variables to Equations (1)-(8) yields [16,17]:

$$
\begin{gathered}
A f^{\prime \prime \prime}+\frac{2 n}{n+1} f f^{\prime \prime}+n\left(-f^{\prime \prime}\right)^{n-1} f^{\prime \prime \prime}-f^{\prime 2}-M^{2} f^{\prime}+g f^{\prime \prime}+\lambda(\theta+N r \phi+N c \chi)=0, \\
A g^{\prime \prime \prime}+g g^{\prime \prime}+n\left(-f^{\prime \prime}\right)^{n-1} g^{\prime \prime \prime}+\left(\frac{2 n}{n+1}\right) f g^{\prime \prime}-M^{2} g^{\prime}-(n-1) g^{\prime \prime} f^{\prime \prime \prime}\left(-f^{\prime \prime}\right)^{n-2} \\
-g^{\prime 2}=0, \\
{\left[\left\{1+R d\left(1+\left(\theta_{w}-1\right) \theta\right)^{3}\right\} \theta^{\prime}\right]^{\prime}+\operatorname{Pr}\left[N t \theta^{\prime 2}+\frac{2 n}{n+1} f \theta^{\prime}+N b \theta^{\prime} \varphi^{\prime}+g \theta^{\prime}\right]=0,} \\
\varphi^{\prime \prime}+\operatorname{LePr}\left[\left(\frac{2 n}{n+1}\right) f \varphi^{\prime}+g \varphi^{\prime}\right]+\frac{N t}{N b} \theta^{\prime \prime}=0, \\
\chi^{\prime \prime}+L b\left[\left(\frac{2 n}{n+1}\right) f \chi^{\prime}+g \chi^{\prime}\right]-\operatorname{Pe}\left[\chi^{\prime} \varphi^{\prime}+(\Omega+\chi) \varphi^{\prime \prime}\right]=0,
\end{gathered}
$$

with the following related boundary conditions $[16,17]$ :

$$
\begin{aligned}
& f(0)=0, g(0)=0, f^{\prime}(0)=1, g^{\prime}(0)=\alpha, \\
& \theta^{\prime}(0)=-B i(1-\theta(0)), N b \phi^{\prime}(0)+N t \theta^{\prime}(0)=0, \quad \chi(0)=1, \\
& f^{\prime}(\infty) \rightarrow 0, g^{\prime}(\infty) \rightarrow 0, \theta(\infty) \rightarrow 0, \varphi(\infty) \rightarrow 0, \chi(\infty) \rightarrow 0,
\end{aligned}
$$

with the material parameter of the Sisko fluid $A$, the Prandtl number $P r$, the buoyancy ratio parameter $N r$, the mixed convection parameter $\lambda$, the bioconvection Rayleigh number $N c$, the magnetic parameter $M$, the velocity ratio parameter $R d$, the radiation parameter $R d$, the temperature ratio parameter $\theta_{w}$, the Brownian motion parameter $N b$, the thermophoresis parameter $N t$, the Lewis number $L e$, the Peclet number $P e$, the bioconvection Lewis number $L b$, and the Biot number $B i$, which are defined as follows:

$$
\begin{aligned}
& A=\frac{R e_{b}^{\frac{2}{n+1}}}{R e_{a}}, R e_{a}=\frac{U_{w} x \rho_{f}}{a}, R e_{b}=\frac{U_{w}^{n-2} x^{n} \rho_{f}}{b}, \operatorname{Pr}=\frac{x U}{\alpha_{1}} R e_{b}^{-\frac{2}{n+1},} \\
& N r\left(=\frac{\left(\rho_{p}-\rho_{f}\right)\left(C_{w}-C_{\infty}\right)}{\rho_{f}\left(1-C_{\infty}\right)\left(T_{w}-T_{\infty}\right) \beta^{* *}}\right), \lambda\left(=\frac{\beta^{* *} g *\left(1-C_{\infty}\right)\left(T_{w}-T_{\infty}\right)}{a U_{w}}\right), \\
& N c\left(=\frac{\gamma *\left(\rho_{m}-\rho_{f}\right)\left(N_{w}-N_{\infty}\right)}{\rho_{f}\left(1-C_{\infty}\right)\left(T_{w}-T_{\infty}\right) \beta^{* *}}\right), M=\frac{\sigma B_{0}^{2}}{(\rho c)_{f}}, \alpha=\frac{d}{c}, R d=\frac{16 \sigma^{*} T_{\infty}^{3}}{3 k^{*} k}, \\
& \theta_{w}=\frac{T_{f}}{T_{\infty}}, B i=\frac{h_{f}}{k} x \operatorname{Re}_{b}^{-\frac{1}{n+1}}, N b=\frac{\tau D_{B} C_{\infty}}{v}, N t=\frac{\tau D_{B}\left(T_{f}-T_{\infty}\right)}{T_{\infty} v}, \\
& L e=\frac{\alpha_{1}}{D_{B}}, \operatorname{Pe}\left(=\frac{b W_{c}}{D_{m}}\right), L b\left(=\frac{v}{D_{m}}\right), B i\left(=\frac{h_{f}}{k} \sqrt{\frac{v}{a}}\right) .
\end{aligned}
$$

The relations for the skin friction coefficient, the local Nusselt number, the local Sherwood number, and the motile density number are presented as follows $[16,17]$ :

$$
\left.\begin{array}{l}
R e_{b}^{-\frac{1}{n+1}} C_{f x}=A f^{\prime \prime}(0)-\left(-f^{\prime \prime}(0)\right)^{n}, \\
\operatorname{Re}_{b}^{-\frac{1}{n+1}} C_{f y}=\frac{V_{w}}{U_{w}}\left(A g^{\prime \prime}(0)+\left(-f^{\prime \prime}(0)\right)^{n-1} g^{\prime \prime}(0)\right) .
\end{array}\right\}
$$




$$
\begin{aligned}
R e_{b}^{-\frac{1}{n+1}} N u_{x}= & -\left[1+R d\left\{1+\left(\theta_{w}-1\right) \theta(0)\right\}^{3}\right] \theta^{\prime}(0) . \\
& R e_{b}^{-\frac{1}{n+1}} S h_{x}=-f^{\prime}(0) . \\
& \operatorname{Re}_{b}^{-\frac{1}{n+1}} N n_{x}=-c^{\prime}(0) .
\end{aligned}
$$

where $\operatorname{Re}_{a}=U_{w} x \rho_{f} / a$ and $R e_{b}=U_{w}^{2-n} x \rho_{f} / b$ signify the local Reynolds numbers.

\section{Numerical Solution}

Owing to the highly nonlinear and coupled nature of the formulated equations, finding an exact equation was not possible. Therefore, the computational shooting algorithm was used in MATLAB (USA). The higher-order differential structure was discretized into first-order differential equations by exploiting appropriate variables. To this end, let us emphasize the following linear operators that were used:

$$
\begin{gathered}
f=s_{1}, f^{\prime}=s_{2}, f^{\prime \prime}=s_{3}, f^{\prime \prime \prime}=s^{\prime}{ }_{3}, g=s_{4}, g^{\prime}=s_{5}, \\
g^{\prime \prime}=s_{6}, g^{\prime \prime \prime}=s^{\prime}{ }_{6}, \theta=s_{7}, \theta^{\prime}=s_{8}, \theta^{\prime \prime}=s^{\prime}, \varphi=s_{9}, \\
\varphi^{\prime}=s_{10}, \varphi^{\prime \prime}=s^{\prime}{ }_{10}, \chi=s_{11}, \chi^{\prime}=s_{12}, \chi^{\prime \prime}=s^{\prime}{ }_{12}, \\
s^{\prime}{ }_{3}=\frac{s_{2}^{2}-\left(\frac{2 n}{n+1} s_{1} s_{3}\right)-s_{4} s_{3}+M^{2} s_{2}-\lambda\left(s_{7}+N r s_{9}+N c s_{11}\right)}{\left(A+n\left(-s_{3}\right)^{n-1}\right)} \\
s^{\prime}{ }_{6}=\frac{(n-1) s_{6} s^{\prime}{ }_{3}\left(-s_{3}\right)^{n-2}-\left(\frac{2 n}{n+1}\right) s_{1} s_{6}+s_{5}^{2}-s_{4} s_{6}+M^{2} s_{5}}{\left(A+n\left(-s_{3}\right)^{n-1}\right)}, \\
s_{8}^{\prime}=\frac{-\operatorname{Pr}\left[\left(\frac{2 n}{n+1}\right) s_{1} s_{8}+s_{4} s_{8}+N b s_{8} s_{10}+N t s_{10}^{2}\right]}{\left[1+R d\left(1+\left(\theta_{w}-1\right)\right)^{3}\right]^{\prime} s_{8}^{3}} \\
s^{\prime}{ }_{10}=-L e \operatorname{Pr}\left[\left(\frac{2 n}{n+1}\right) s_{1} s_{10}+s_{4} s_{10}\right]-\frac{N t}{N b} s^{\prime}{ }_{8}, \\
s_{12}^{\prime}=-L b\left[\left(\frac{2 n}{n+1}\right) s_{1} s_{12}+s_{4} s_{12}\right]+P e\left[s_{12} s_{10}+\left(\Omega+s_{11}\right) s^{\prime}{ }_{10}\right] .
\end{gathered}
$$

Similarly the boundary conditions were transformed as follows:

$$
\begin{gathered}
s_{1}(0)=0, s_{4}(0)=0, s_{2}(0)=1, s_{5}(0)=\alpha, \\
s_{8}(0)=-B i\left(1-s_{7}(0)\right), N b s_{10}+N t s_{8}=0, \chi^{\prime}(0)=1, \\
s_{2} \rightarrow 0, s_{5} \rightarrow 0, s_{7} \rightarrow 0, s_{9} \rightarrow 0, s_{11} \rightarrow 0 \text { as } \zeta \rightarrow \infty .
\end{gathered}
$$

With an iterative process, the numerical simulations were repeated until an accuracy of $10^{-5}$ was achieved.

\section{Solution Verification}

The obtained numerical results were verified to confirm the solution's accuracy. To this end, the present results were compared as a limiting case with the work of Hayat et al. [17] in Table 1. An excellent solution accuracy between both analyses was noted for $n=0.5$ and $n=1.5$. 
Table 1. Comparative analysis for the obtained numerical solution with Hayat et al. [17] when $M=0.2, \alpha=0.1, \lambda=N r=N c=0$.

\begin{tabular}{ccccc}
\hline & \multicolumn{2}{c}{ Hayat et al. [17] } & \multicolumn{2}{c}{ Present Results } \\
\cline { 2 - 5 } $\boldsymbol{A}$ & \multicolumn{2}{c}{$-\boldsymbol{R} \boldsymbol{e}_{\boldsymbol{b}}^{-\frac{1}{n+1}} \boldsymbol{C}_{f x}$} & \multicolumn{2}{c}{$-\boldsymbol{R e}_{\boldsymbol{b}}^{-\frac{1}{n+1}} \boldsymbol{C}_{f x}$} \\
\cline { 2 - 5 } & $n=1$ & $n=2$ & 1.0395 & $n=2$ \\
\hline 0.0 & 1.0394 & 1.0050 & 1.2731 & 1.0048 \\
0.5 & 1.2730 & 1.2076 & 1.4700 & 1.4714 \\
\hline
\end{tabular}

\section{Results and Discussion}

The physical outcomes for the bioconvection flow of a Sisko nanofluid for the modeled parameters are conveyed in this section. Since it was already communicated that a Sisko fluid model captures the dynamics of the shear-thinning $(n>1)$ and shear-thickening $(n<1)$ features, all the graphical results were prepared with such consequences in mind. Figure 2 describes the nature of the mixed convection parameter $\lambda$ for the velocity profile $f^{\prime}$ when $n=0.5$ and $n=1.5$. An increased velocity profile was observed for higher $\lambda$ values. However, the increase in the velocity was comparatively higher for the shear-thinning case with $n=1.5$. The physical assessment of this flow dynamic was attributed to the fact that the mixed convection constant influenced the buoyancy forces. An increase in $\lambda$ increased the buoyancy force, and as such, the velocity profile had an increased range. Figure 3 shows the evaluation of $f^{\prime}$ for the bioconvection Nc. It was found that an increasing behavior of the bioconvection Rayleigh number decreased the velocity distribution for both cases $(n=0.5$ and 1.5). The effects of the buoyancy ratio parameter $\mathrm{Nr}$ on the velocity profile $f^{\prime}$ are depicted in Figure 4. From these curves, it was found that the buoyancy ratio parameter reduced the velocity concentration $f^{\prime}$ for both shear thinning and thickening ( $n=0.5$ and 1.5). Figure 5 reveals the outcomes of the magnetic parameter $M$ regarding the prediction of shear thickening and thinning aspects for the velocity $f^{\prime}$. The velocity $f^{\prime}$ reduced with a higher magnetic parameter. Physically, the magnetic parameter influenced the Lorentz force, which controlled the fluid motion parameters in the flow system. The significances of the magnetic parameter $M$ for velocity $g^{\prime}$ is revealed in Figure 6. It was perceived that the velocity of fluid $g^{\prime}$ reduced with the magnetic parameter. For the shearthickening behavior, the reduction in the velocity was relatively slow. The influence of $\theta_{w}$ on the temperature profile $\theta$ for both cases is presented in Figure 7. Again, the results were prepared using $n=0.5$ and $n=1.5$. It was found that increasing values of the temperature ratio parameter boosted the nanofluid temperature. The thermal radiation was more effective at enhancing the nanofluid temperature. The variation of the Prandtl number $\operatorname{Pr}$ on the temperature profile $\theta$ is presented in Figure 8. It was found that higher values of the Prandtl number decreased the temperature of the fluid $\theta$ for both values of the behavior index $n$. Since the Prandtl number is the ratio of the momentum diffusivity to the thermal diffusivity, an increase in the Prandtl number enhanced the momentum diffusivity but slowed the thermal diffusivity, which caused a reduction in the nanofluid temperature. Figure 9 presents the results for the Biot number $B i$ on the temperature $\theta$. The temperature distribution $\theta$ increased the Biot number, which was more comprehensive for shear-thinning case. The physical aspects of such an enhanced graphical trend were due to the fact that the Biot number is related to the heat transfer coefficient. The outcome of the Brownian motion constant $\mathrm{Nb}$ on $\phi$, subject to the shear thinning $n=1.5$ and thickening $n=0.5$ perspectives, is reflected in Figure 10. Increasing the values of the Brownian motion parameter decreased the concentration of the nanoparticles. The decreasing association of $\phi$ with $\mathrm{Nb}$ was expected because it replicated the opposite relation with the nondimensional $\phi$. To scrutinize the domination of the thermophoresis parameter $N t$ on the volumetric concentration field $\phi$, Figure 11 is presented. It was found that increasing the magnitude of the thermophoresis parameter increased the volumetric concentration of the nanoparticles $\phi$. Physically, the thermophoresis phenomenon describes the heated nanoparticles that 
wandered to the low-temperature space. Figure 12 presents the outcomes of the Lewis number Le on $\phi$ in view of the shear thinning and shear thickening parameters. Increasing the Lewis number decreased the concentration distribution $\phi$. Physically, the decreasing trend in $\phi$ was deemed to be the reverse relation with mass diffusivity. To disclose the increase in the Peclet number $P e$ on the microorganisms field $\chi$, Figure 13 is presented. The summarized graphical trend shows that $\chi$ decreased as $P e$ increased. The reverse effect of the Peclet number on the diffusivity of the motile density caused such a trend. In order to analyze the behavior of $\chi$ due to $L b$, Figure 14 was plotted. An abated profile of $\chi$ was noted due to the increased values of $L b$.

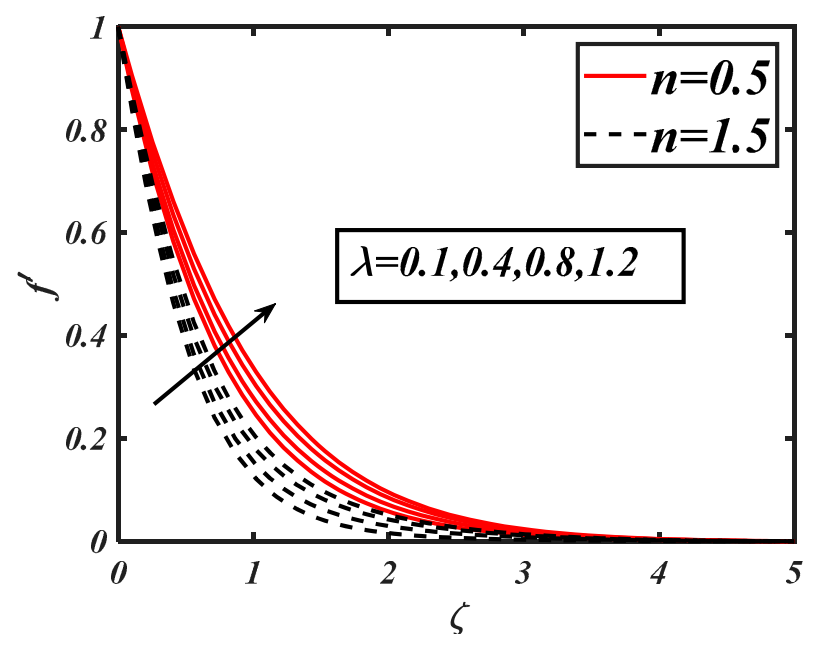

Figure 2. Change in $f^{\prime}(\zeta)$ with $\lambda$.

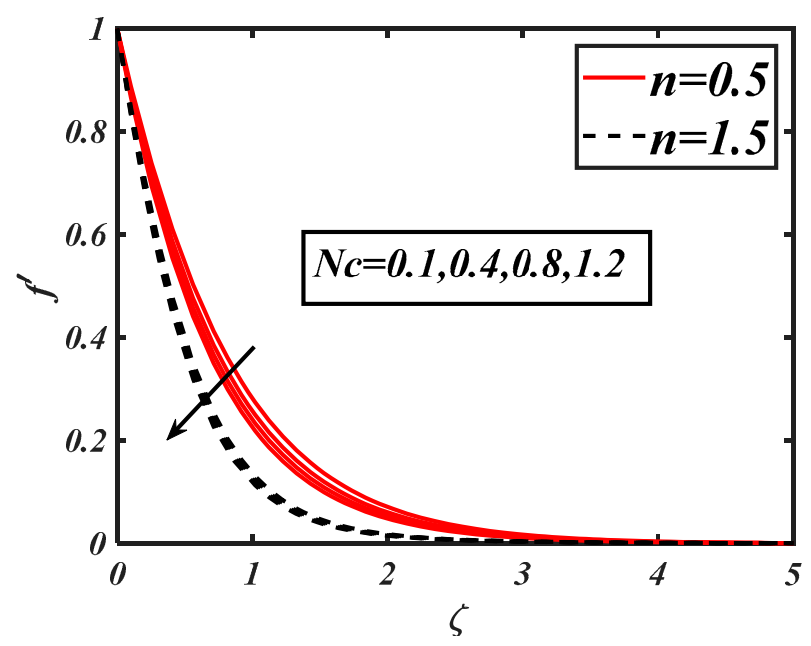

Figure 3. Change in $f^{\prime}(\zeta)$ with $N c$. 


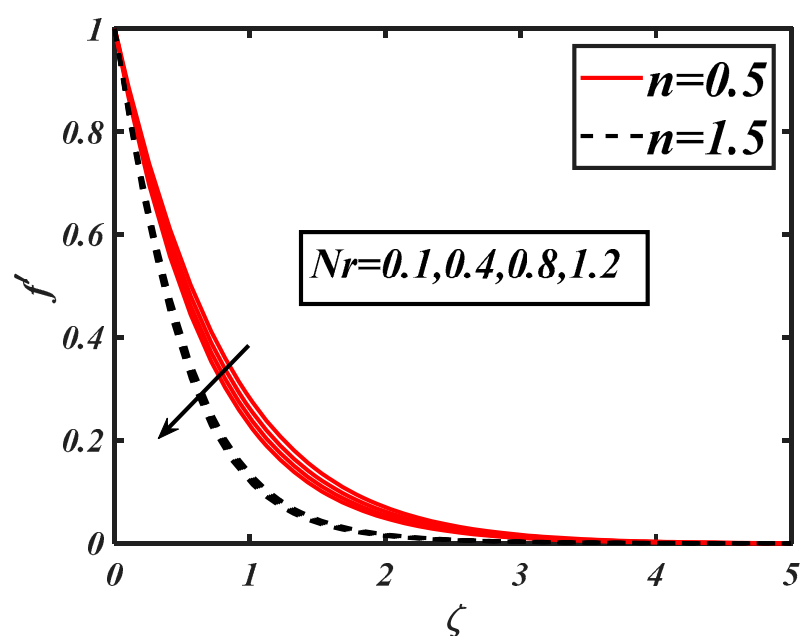

Figure 4. Change in $f^{\prime}(\zeta)$ with $N r$.

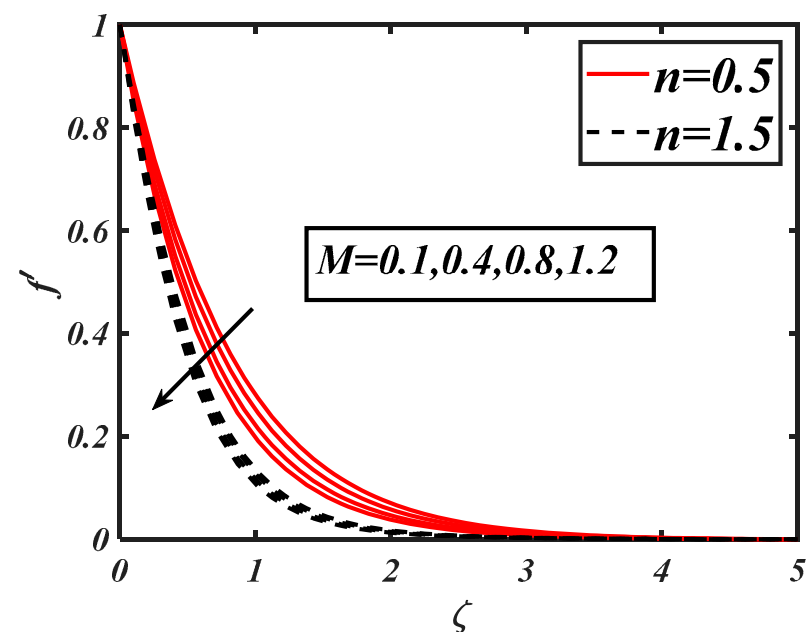

Figure 5. Change in $f^{\prime}(\zeta)$ with $M$.

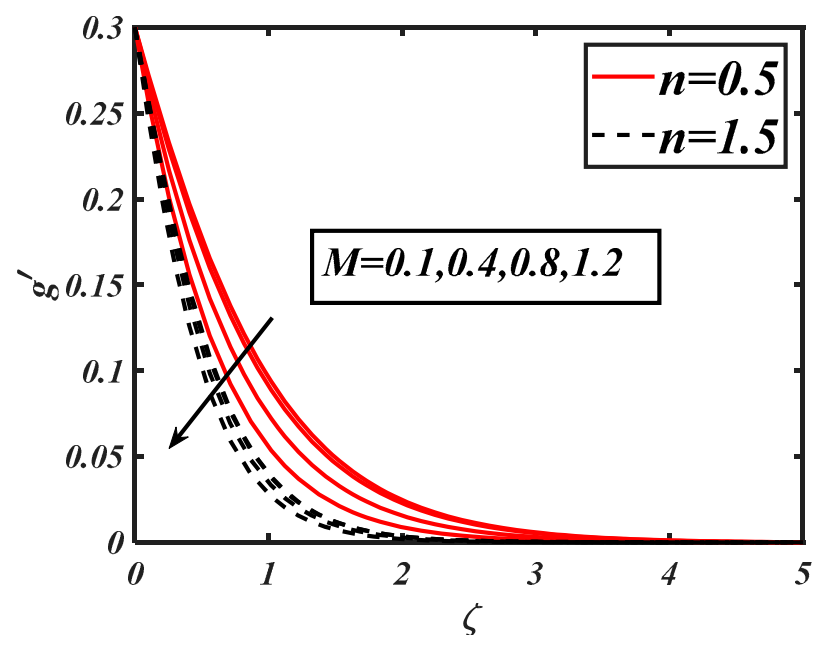

Figure 6. Change in $g^{\prime}(\zeta)$ with $M$. 


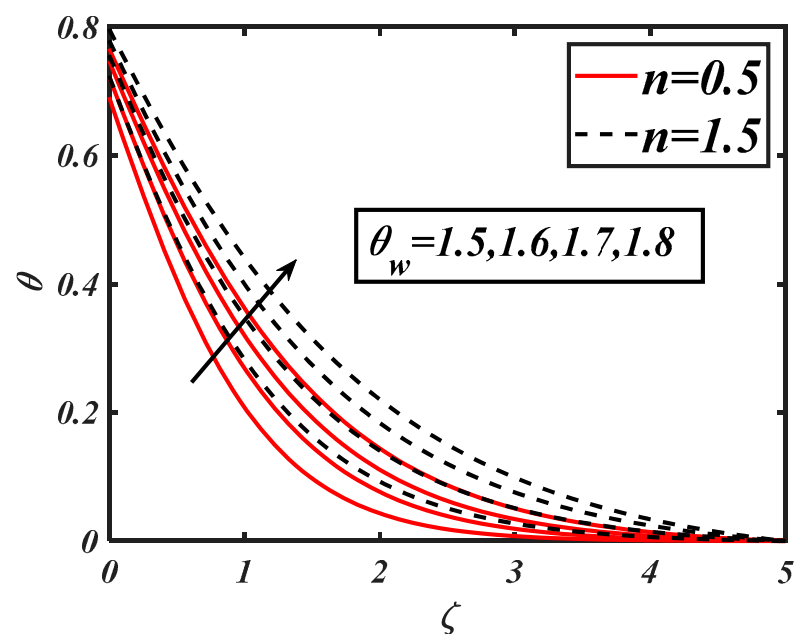

Figure 7. Change in $\theta(\zeta)$ with $\theta_{w}$.

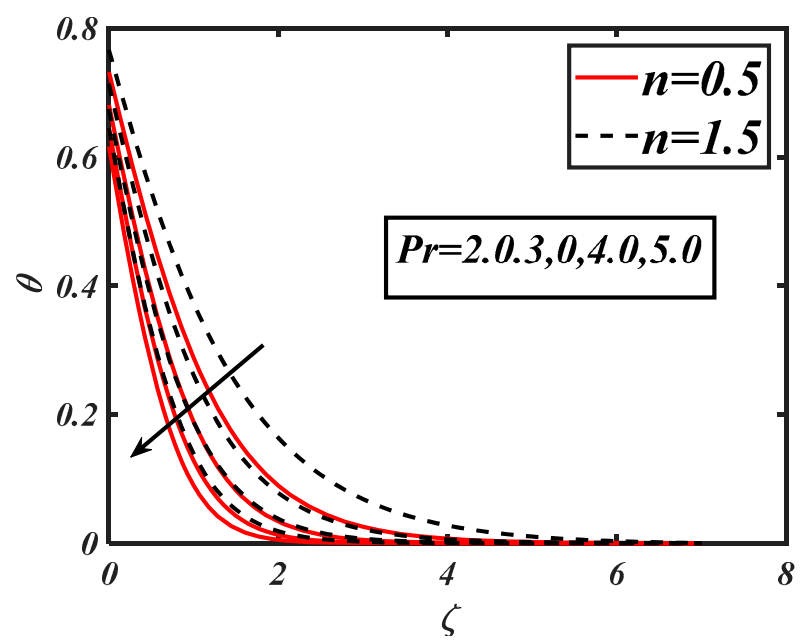

Figure 8. Change in $\theta(\zeta)$ with $\operatorname{Pr}$.

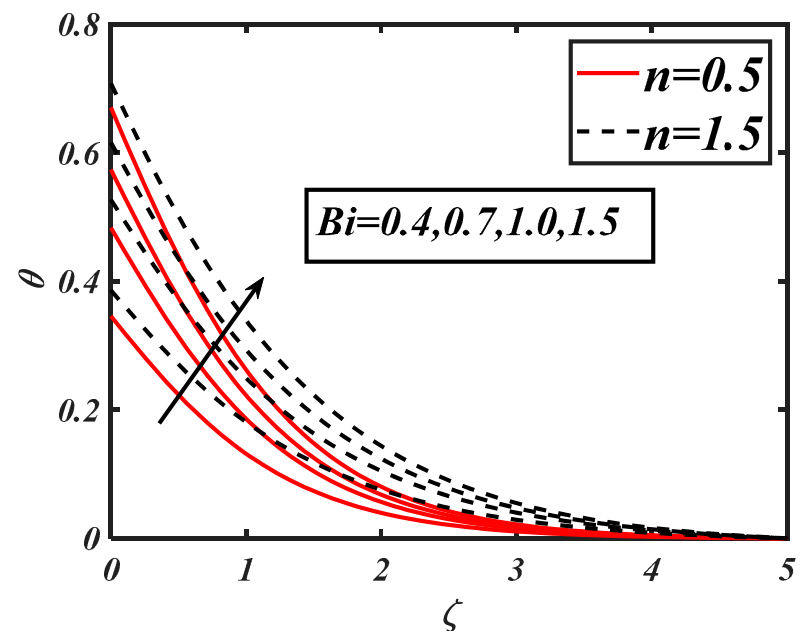

Figure 9. Change in $\theta(\zeta)$ with $B i$. 


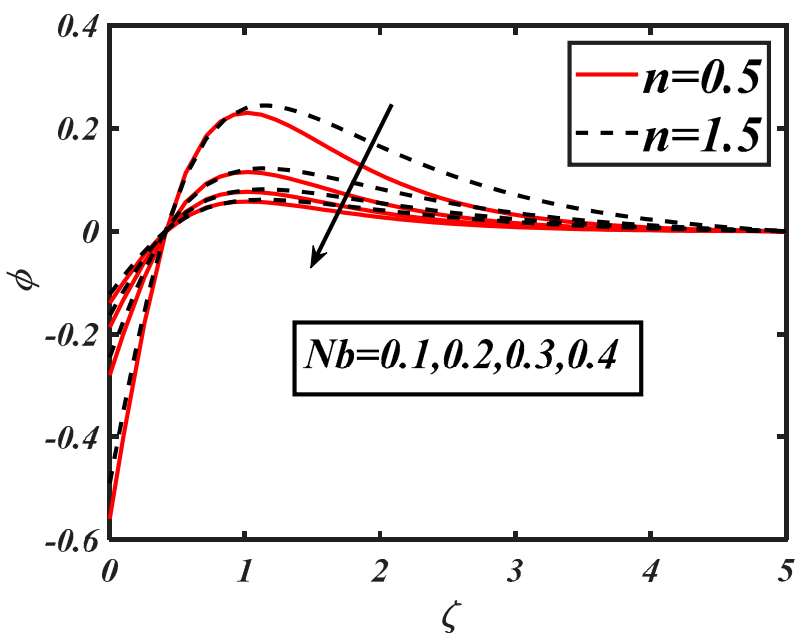

Figure 10. Change in $\phi(\zeta)$ with $N b$.

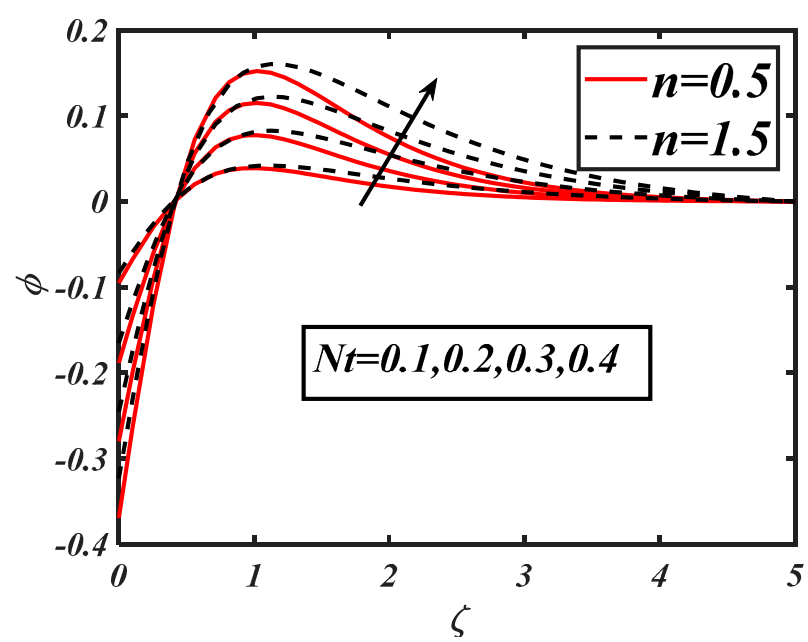

Figure 11. Change in $\phi(\zeta)$ with $N t$.

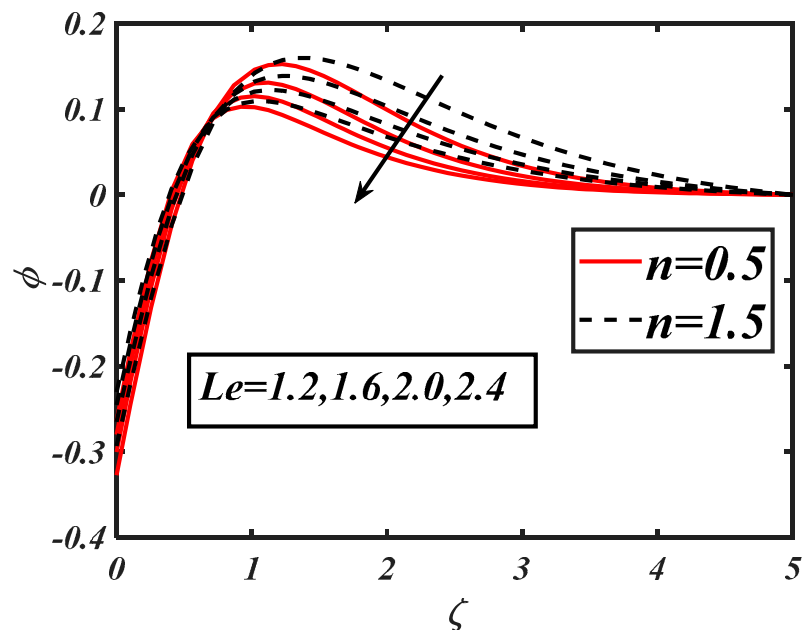

Figure 12. Change in $\phi(\zeta)$ with Le. 


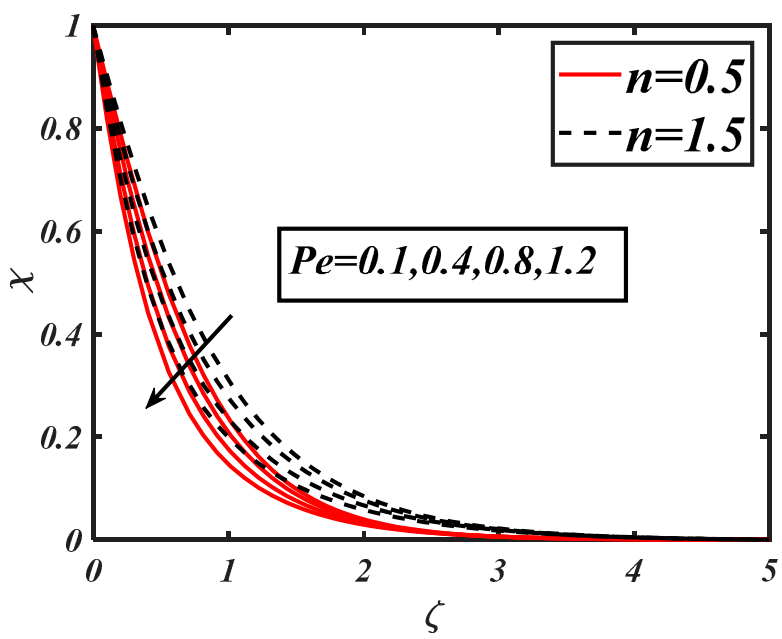

Figure 13. Change in $\chi(\zeta)$ with $P e$.

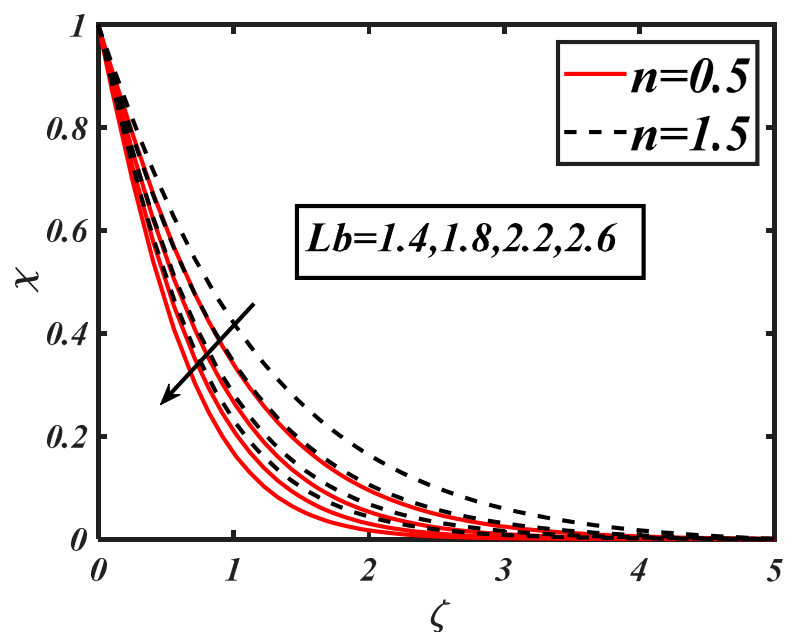

Figure 14. Change in $\chi(\zeta)$ with $L b$.

Table 2 presents the impact of the local skin friction coefficients along $x$-axis $-f^{\prime \prime}(0)$ with respect to various flow parameters when $n=0.5$ and $n=1.5$. It was noted that an increase in the wall shear force acting along the $x$-direction produced increases in $N r, M$ and $N c$, which were more prominent when $n=1.5$. The change in $-g^{\prime \prime}(0)$ due to the flow parameters are presented in Table 3. An increasing change in $-g^{\prime \prime}(0)$ was observed for increases in $N r$ and $N c$, while a contrasting trend was observed for an increase in $\lambda$. Table 4 depicts the salient features of the Nusselt number $-\theta^{\prime}(0)$ for different flow parameters. This analysis was performed with the presence and absence of Brownian motion $\mathrm{Nb}$ and the thermophoresis parameter $N t$. It is clearly highlighted that the increasing variation in $-\theta^{\prime}(0)$ due to increases in $\lambda, P r$, and $R d$ was more pronounced in the presence of $N b$ and $N t$. Table 5 presents the numerical data for the local Sherwood number $-\phi^{\prime}(0)$. With increases in $\mathrm{Pr}$ and $\mathrm{Nb}$, the local Sherwood number increased. Table 6 highlights the physical significance of the local microorganism number in terms of various parameters. It was clearly noticed that the motile density number was at a maximum when $P e$ and $L b$ were at their maximum values. 
Table 2. Numerical amplitudes of the local skin friction coefficient with respect to various parameters.

\begin{tabular}{|c|c|c|c|c|c|}
\hline \multicolumn{4}{|c|}{ Parameters } & \multicolumn{2}{|c|}{$-f^{\prime \prime}(0)$} \\
\hline$\lambda$ & $\mathrm{Nr}$ & $N c$ & $M$ & $n=0.5$ & $n=1.5$ \\
\hline 0.2 & & & & 1.0726 & 1.4402 \\
\hline 0.4 & 0.1 & 0.1 & 0.4 & 1.0709 & 1.4392 \\
\hline 0.8 & & & & 1.0675 & 1.4370 \\
\hline \multirow{3}{*}{0.1} & 0.8 & & & 1.2735 & 1.6531 \\
\hline & 1.6 & - & - & 1.2746 & 1.6554 \\
\hline & 2.2 & & & 1.2748 & 1.6573 \\
\hline \multirow{3}{*}{-} & & 0.8 & & 1.2999 & 1.6796 \\
\hline & - & 1.6 & - & 1.3308 & 1.7127 \\
\hline & & 2.2 & & 1.3542 & 1.7380 \\
\hline \multirow{3}{*}{-} & & & 0.2 & 1.1952 & 1.5934 \\
\hline & - & - & 0.4 & 1.2731 & 1.6512 \\
\hline & & & 0.8 & 1.4160 & 1.7614 \\
\hline
\end{tabular}

Table 3. Numerical amplitudes of the local skin coefficient with respect to various parameters.

\begin{tabular}{|c|c|c|c|c|c|}
\hline \multicolumn{4}{|c|}{ Parameters } & \multicolumn{2}{|c|}{$-g^{\prime \prime}(0)$} \\
\hline$\lambda$ & $\mathrm{Nr}$ & $N c$ & $M$ & $n=0.5$ & $n=1.5$ \\
\hline 0.2 & \multirow{3}{*}{0.1} & \multirow{3}{*}{0.1} & \multirow{3}{*}{0.4} & 0.0911 & 0.1477 \\
\hline 0.4 & & & & 0.0910 & 0.1446 \\
\hline 0.8 & & & & 0.0908 & 0.1444 \\
\hline \multirow{3}{*}{0.1} & 0.8 & \multirow{3}{*}{-} & \multirow{3}{*}{-} & 0.2983 & 0.4405 \\
\hline & 1.6 & & & 0.2990 & 0.4499 \\
\hline & 2.2 & & & 0.2997 & 0.4504 \\
\hline \multirow{3}{*}{-} & \multirow{3}{*}{-} & 0.8 & \multirow{3}{*}{-} & 0.2978 & 0.4367 \\
\hline & & 1.6 & & 0.2988 & 0.4435 \\
\hline & & 2.2 & & 0.2996 & 0.4521 \\
\hline \multirow{3}{*}{-} & \multirow{3}{*}{-} & \multirow{3}{*}{-} & 0.2 & 0.2816 & 0.4307 \\
\hline & & & 0.4 & 0.2986 & 0.4410 \\
\hline & & & 0.8 & 0.3633 & 0.4856 \\
\hline
\end{tabular}

Table 4. Numerical amplitudes of the local Nusselt number with respect to various parameters.

\begin{tabular}{|c|c|c|c|c|c|c|c|c|c|}
\hline \multicolumn{6}{|c|}{ Parameters } & \multicolumn{2}{|c|}{$\begin{array}{c}-\theta^{\prime}(0) \\
(N t=N b=0.3)\end{array}$} & \multicolumn{2}{|c|}{$\begin{array}{c}-\theta^{\prime}(0) \\
(N t=N b=0.0)\end{array}$} \\
\hline$\lambda$ & $\mathrm{Nr}$ & $N c$ & $M$ & $P r$ & $R d$ & $n=0.5$ & $n=1.5$ & $n=0.5$ & $n=1.5$ \\
\hline $\begin{array}{l}0.2 \\
0.4 \\
0.8 \\
\end{array}$ & 0.1 & 0.1 & 0.4 & 2.0 & 0.6 & $\begin{array}{l}0.3885 \\
0.3891 \\
0.3932 \\
\end{array}$ & $\begin{array}{l}0.5128 \\
0.5234 \\
0.5297\end{array}$ & $\begin{array}{l}0.3371 \\
0.3154 \\
0.2904 \\
\end{array}$ & $\begin{array}{l}0.4231 \\
0.4346 \\
0.4454\end{array}$ \\
\hline 0.1 & $\begin{array}{l}0.8 \\
1.6 \\
2.2\end{array}$ & - & - & - & - & $\begin{array}{l}0.5360 \\
0.5352 \\
0.5346 \\
\end{array}$ & $\begin{array}{l}0.4700 \\
0.4686 \\
0.4676 \\
\end{array}$ & $\begin{array}{l}0.4267 \\
0.4054 \\
0.3909 \\
\end{array}$ & $\begin{array}{l}0.4134 \\
0.3889 \\
0.3667 \\
\end{array}$ \\
\hline- & - & $\begin{array}{l}0.8 \\
1.6 \\
2.2\end{array}$ & - & - & - & $\begin{array}{l}0.5347 \\
0.5325 \\
0.5307\end{array}$ & $\begin{array}{l}0.4686 \\
0.4655 \\
0.4631\end{array}$ & $\begin{array}{l}0.4378 \\
0.4205 \\
0.4056\end{array}$ & $\begin{array}{l}0.4102 \\
0.4067 \\
0.3956\end{array}$ \\
\hline- & - & - & $\begin{array}{l}0.2 \\
0.4 \\
0.8\end{array}$ & - & - & $\begin{array}{l}0.5443 \\
0.5367 \\
0.5199\end{array}$ & $\begin{array}{l}0.4753 \\
0.4711 \\
0.4617\end{array}$ & $\begin{array}{l}0.4479 \\
0.4334 \\
0.4056\end{array}$ & $\begin{array}{l}0.4156 \\
0.3924 \\
0.3854\end{array}$ \\
\hline- & - & - & - & $\begin{array}{l}2.5 \\
3.0 \\
3.5\end{array}$ & - & $\begin{array}{l}0.5921 \\
0.6383 \\
0.6775 \\
\end{array}$ & $\begin{array}{l}0.5259 \\
0.5733 \\
0.6145 \\
\end{array}$ & $\begin{array}{l}0.5303 \\
0.5554 \\
0.5934 \\
\end{array}$ & $\begin{array}{l}0.4865 \\
0.5276 \\
0.5467 \\
\end{array}$ \\
\hline- & - & - & - & - & $\begin{array}{l}0.8 \\
1.4 \\
1.8\end{array}$ & $\begin{array}{l}0.4917 \\
0.4271 \\
0.3963\end{array}$ & $\begin{array}{l}0.4288 \\
0.3713 \\
0.3453\end{array}$ & $\begin{array}{l}0.4165 \\
0.3704 \\
0.32565\end{array}$ & $\begin{array}{l}0.3776 \\
0.3467 \\
0.3156\end{array}$ \\
\hline
\end{tabular}


Table 5. Numerical amplitudes of the local Sherwood number with respect to various parameters.

\begin{tabular}{|c|c|c|c|c|c|c|c|c|c|}
\hline \multicolumn{8}{|c|}{ Parameters } & \multicolumn{2}{|c|}{$-\phi^{\prime}(0)$} \\
\hline$\lambda$ & $N r$ & $N c$ & $M$ & $P r$ & $N t$ & $L e$ & $N b$ & $n=0.5$ & $n=1.5$ \\
\hline 0.2 & & & & & & & & 0.8145 & 0.7954 \\
\hline 0.4 & 0.1 & 0.1 & 0.4 & 2.0 & 0.3 & 2.0 & - & 0.8256 & 0.8167 \\
\hline 0.8 & & & & & & & & 0.9310 & 0.8966 \\
\hline \multirow{3}{*}{0.1} & 0.8 & & & & & & & 0.8040 & 0.7050 \\
\hline & 1.6 & - & - & - & - & - & - & 0.8028 & 0.7030 \\
\hline & 2.2 & & & & & & & 0.8019 & 0.7014 \\
\hline \multirow{3}{*}{-} & & 0.8 & & & & & & 0.8021 & 0.7029 \\
\hline & - & 1.6 & - & - & - & - & - & 0.7987 & 0.6983 \\
\hline & & 2.2 & & & & & & 0.7960 & 0.6947 \\
\hline \multirow{3}{*}{-} & & & 0.2 & & & & & 0.8165 & 0.7129 \\
\hline & - & - & 0.4 & - & - & - & - & 0.8050 & 0.7067 \\
\hline & & & 0.8 & & & & & 0.7799 & 0.6925 \\
\hline \multirow{3}{*}{-} & & & & 2.5 & & & & 0.8882 & 0.7889 \\
\hline & - & - & - & 3.0 & & - & - & 0.9575 & 0.8600 \\
\hline & & & & 3.5 & & & & 1.0162 & 0.9218 \\
\hline \multirow{3}{*}{-} & & & & & 0.1 & & & 0.8180 & 0.7870 \\
\hline & - & - & - & - & 0.4 & - & - & 0.8045 & 0.7756 \\
\hline & & & & & 0.8 & & & 0.7956 & 0.7434 \\
\hline \multirow{3}{*}{-} & & & & & & 3.0 & & 0.7991 & 0.7012 \\
\hline & - & - & - & - & - & 4.0 & & 0.7952 & 0.6976 \\
\hline & & & & & & 5.0 & & 0.7922 & 0.6950 \\
\hline \multirow{3}{*}{-} & & & & & & & 0.1 & 0.8990 & 0.7854 \\
\hline & - & - & - & - & - & - & 0.4 & 1.0234 & 0.7901 \\
\hline & & & & & & & 0.8 & 1.1014 & 0.9912 \\
\hline
\end{tabular}

Table 6. Numerical amplitudes of the local microorganism number with respect to various parameters.

\begin{tabular}{|c|c|c|c|c|c|c|c|}
\hline \multicolumn{6}{|c|}{ Parameters } & \multicolumn{2}{|c|}{$-\chi^{\prime}(0)$} \\
\hline$\lambda$ & $N r$ & $N c$ & $M$ & $P e$ & $L b$ & $n=0.5$ & $n=1.5$ \\
\hline 0.2 & & & & & & 1.0853 & 0.9534 \\
\hline 0.4 & 0.1 & 0.1 & 0.4 & 0.1 & 2.0 & 1.1012 & 0.9611 \\
\hline 0.8 & & & & & & 1.1145 & 0.9917 \\
\hline \multirow{3}{*}{0.1} & 0.8 & & & & & 1.0751 & 0.9429 \\
\hline & 1.6 & - & - & - & - & 1.0738 & 0.9405 \\
\hline & 2.2 & & & & & 1.0728 & 0.9386 \\
\hline \multirow{3}{*}{-} & & 0.8 & & & & 1.0724 & 0.9378 \\
\hline & - & 1.6 & - & - & - & 1.0678 & 0.9336 \\
\hline & & 2.2 & & & & 1.0642 & 0.9287 \\
\hline \multirow{3}{*}{-} & & & 0.2 & & & 1.0916 & 0.9539 \\
\hline & - & - & 0.4 & - & - & 1.0762 & 0.9450 \\
\hline & & & 0.8 & & & 1.0422 & 0.9243 \\
\hline \multirow{3}{*}{-} & & & & 0.5 & & 1.3580 & 1.2022 \\
\hline & - & - & - & 1.0 & - & 1.7185 & 1.5295 \\
\hline & & & & 1.5 & & 2.0874 & 1.8625 \\
\hline \multirow{3}{*}{-} & & & & & 3.0 & 0.2375 & 0.2285 \\
\hline & - & - & - & - & 4.0 & 0.2382 & 0.2290 \\
\hline & & & & & 5.0 & 0.2388 & 0.2293 \\
\hline
\end{tabular}




\section{Conclusions}

The three-dimensional thermally radiative flow of a Sisko nanofluid fluid containing microorganisms over a stretched surface was examined. Quantitative analyses for all physical flow parameters in view of the shear-thinning and shear-thickening aspects was comprehensively discussed. Numerical simulations via the shooting technique were performed. The Brownian motion and thermophoresis features were investigated by incorporating the Buongiorno model. The main outcomes are listed as follows:

$>$ An increase in the velocity due to the mixed convection parameter was observed, which was enhanced in the shear-thinning case.

$>$ The hindering effects on the velocity due to the bioconvection Rayleigh number was relatively slower when shear-thickening effects were dominant.

$>$ The nanofluid temperature was enhanced due to the Biot number and surface-heating source parameter. The enhancement in temperature in the case of shear thickening was qualitatively slower as compared to the shear-thinning case.

$>$ An increase in the nanofluid concentration due to the thermophoretic parameter was more progressive when shear-thinning features were considered.

$>$ The microorganism profile decreased with the bioconvection Lewis number and Peclet number.

Author Contributions: H.G.-J., presents the results analysis and physical explanation of problem; H.W., presented the flow model; S.U.K., computed the solution; M.I.K., made the literature survey; S.F., analyzed the results; S.H., write the discussion of results. All authors have read and agreed to the published version of the manuscript.

Funding: This research received no external funding.

Institutional Review Board Statement: Not applicable.

Informed Consent Statement: Not applicable.

Data Availability Statement: Not applicable.

Conflicts of Interest: The authors declare no conflict of interest.

\section{Abbreviations}

\begin{tabular}{|c|c|c|c|}
\hline$u, v$ & velocity components $\left(\mathrm{m} \cdot \mathrm{s}^{-1}\right)$ & $x, y$ & coordinate axes (m) \\
\hline$T$ & temperature $(\mathrm{K})$ & C & nanoparticles concentration $\left(\mathrm{kg} \cdot \mathrm{m}^{-3}\right)$ \\
\hline$v$ & kinematic viscosity $\left(\mathrm{m}^{2} \cdot \mathrm{s}^{-1}\right)$ & $T_{w}$ & wall temperature $(\mathrm{K})$ \\
\hline$T_{\infty}$ & free stream temperature $(\mathrm{K})$ & $C_{\infty}$ & ambient concentration $\left(\mathrm{kg} \cdot \mathrm{m}^{-3}\right)$ \\
\hline$\rho_{f}$ & density $\left(\mathrm{kg} \cdot \mathrm{m}^{-3}\right)$ & $D_{B}$ & Brownian diffusion coefficient $\left(\mathrm{m}^{2} \cdot \mathrm{s}^{-1}\right)$ \\
\hline$D_{T}$ & $\begin{array}{l}\text { thermophoresis diffusion } \\
\text { coefficient }\left(\mathrm{m}^{2} \cdot \mathrm{s}^{-1}\right)\end{array}$ & $\mu$ & dynamic viscosity $\left(\mathrm{N} \cdot \mathrm{s} \cdot \mathrm{m}^{-2}\right)$ \\
\hline$g$ & gravity & $\tau$ & heat capacity ratio \\
\hline$k^{*}$ & mean absorption coefficient & $D_{m}$ & microorganism diffusion constant \\
\hline$\sigma^{*}$ & Stefan-Boltzmann constant & $q_{r}$ & radiative flux \\
\hline$\hat{b}$ & chemotaxis constant & $\gamma$ & volume suspension coefficient \\
\hline$(a, b)$ & Sisko fluid materials constants & $\sigma_{1}$ & electrical conductivity \\
\hline$B_{0}$ & magnetic field strength & $\beta^{* *}$ & volume expansion coefficient \\
\hline$\rho_{p}$ & density of nanoparticles & $\rho_{m}$ & density of microorganisms \\
\hline$A$ & Sisko fluid material parameter & $\mathrm{Pr}$ & Prandtl number \\
\hline$N r$ & buoyancy ratio parameter & $\lambda$ & mixed convection parameter \\
\hline$N c$ & bioconvection Rayleigh number & $M$ & magnetic parameter \\
\hline Rd & radiation parameter & $\theta_{w}$ & temperature ratio parameter \\
\hline$N t$ & thermophoresis parameter & $\mathrm{Nb}$ & Brownian motion parameter \\
\hline Le & Lewis number & $P e$ & Peclet number \\
\hline$L b$ & bioconvection Lewis number & $B i$ & Biot number \\
\hline $\operatorname{Re}$ & local Reynolds number & $N u_{x}$ & local Nusselt number \\
\hline$S h_{x}$ & local Sherwood number & $N n_{x}$ & motile density number \\
\hline
\end{tabular}




\section{References}

1. Choi, S.U.S.; Eastman, J. Enhancing thermal conductivity of fluids with nanoparticles. ASME 2001, 231, 718-720.

2. Buongiorno, J. Convective transport in nanofluids. J. Heat Transf. 2006, 128, 240-250. [CrossRef]

3. Iqbal, N.; Yasmin, H.; Kometa, B.K.; Attiya, A.A. Effects of convection on Sisko fluid with peristalsis in an asymmetric channel. Math. Comput. Appl. 2020, 25, 52. [CrossRef]

4. Ali, M.; Irfan, M.; Khan, W.A.; Sultan, F.; Shahzad, M.; Khan, M. Physical significance of chemical processes and Lorentz's forces aspects on Sisko fluid flow in curved configuration. Soft Comput. 2020, 24, 16213-16223. [CrossRef]

5. Chaudhuri, S.; Rathore, S.K. An analytical investigation of pressure-driven flow and heat transfer of a Sisko fluid flowing through parallel plates with viscous dissipation. Sadhana 2020, 45, 1-17. [CrossRef]

6. Nabil, T.; Mostapha, D.R. Hall current and joule heating effects on peristaltic flow of a Sisko fluid with mild stenosis through a porous medium in a tapered artery with slip and convective boundary conditions. Sains Malays. 2020, 49, 1175-1190.

7. Toghraie, D.; Esfahani, N.N.; Zarringhalam, M.; Shirani, N.; Rostami, S. Blood flow analysis inside different arteries using non-Newtonian Sisko model for application in biomedical engineering. Comput. Methods Progr. Biomed. 2020, 190, 105338. [CrossRef] [PubMed]

8. Agoor, B.M.; Sayed-Ahmed, M.E.; Alam, H. Peristaltic flow with heat transfer on Sisko fluid in a ciliated arteries. Int. J. Fluid Mech. Therm. Sci. 2020, 6, 70-78. [CrossRef]

9. Ferdows, M.; Reddy, M.G.; Sun, S.; Alzahrani, F. Two-dimensional gyrotactic microorganisms flow of hydromagnetic power-law nanofluid past an elongated sheet. Adv. Mech. Eng. 2019, 11. [CrossRef]

10. Gangadhar, K.; Kannan, T.; Sakthivel, G.; Dasaradha Ramaiah, K. Unsteady free convective boundary layer flow of a nanofluid past a stretching surface using a spectral relaxation method. Int. J. Ambient Energy 2020, 41, 609-616. [CrossRef]

11. Jawad, M.; Shah, Z.; Khan, A.; Khan, W.; Kumam, P.; Islam, S. Entropy generation and heat transfer analysis in MHD unsteady rotating flow for aqueous suspensions of carbon nanotubes with nonlinear thermal radiation and viscous dissipation effect. Entropy 2019, 21, 492. [CrossRef] [PubMed]

12. Ali, M.; Sultan, F.; Khan, W.A.; Shahzad, M.; Arif, H. Important features of expanding/contracting cylinder for cross magnetonanofluid flow. Chaos Solitons Fractals 2020, 133, 109656. [CrossRef]

13. Nisar, Z.; Hayat, T.; Alsaedi, A.; Ahmad, B. Significance of activation energy in radiative peristaltic transport of Eyring-Powell nanofluid. Int. Commun. Heat Mass Transf. 2020, 116, 104655. [CrossRef]

14. Muhammad, T.; Waqas, H.; Khan, S.A.; Ellahi, R.; Sait, S.M. Significance of nonlinear thermal radiation in 3D Eyring-Powell nanofluid flow with Arrhenius activation energy. J. Therm. Anal. Calorim. 2020, 143, 1-16. [CrossRef]

15. Muhammad, K.; Hayat, T.; Alsaedi, A.; Ahmad, B. Melting heat transfer in squeezing flow of base fluid (water), nanofluid (CNTs + water), and hybrid nanofluid (CNTs + CuO + water). J. Therm. Anal. Calorim. 2020, 1-18. [CrossRef]

16. Hayat, T.; Taseer Muhammad, B.; Ahmad, S.; Shehzad, A. Impact of magnetic field in three-dimensional flow of Sisko nanofluid with convective condition. J. Magn. Magn. Mater. 2016, 413, 1-8. [CrossRef]

17. Hayat, T.; Taseer Muhammad, B.; Ahmad, S.; Shehzad, A.; Alsaedi, A. On three-dimensional boundary layer flow of Sisko nanofluid with magnetic field effects. Adv. Powder Technol. 2016, 27, 504-512. [CrossRef]

18. Pal, D.; Mandal, G. Magnetohydrodynamic stagnation-point flow of Sisko nanofluid over a stretching sheet with suction. Propuls. Power Res. 2020, 9, 408-422. [CrossRef]

19. Khan, M.I. Transportation of hybrid nanoparticles in forced convective Darcy-Forchheimer flow by a rotating disk. Int. Commun Heat Mass Transf. 2021, 122, 105177. [CrossRef]

20. Chu, Y.M.; Khan, M.I.; Khan, N.B.; Kadry, S.; Khan, S.U.; Tlili, I.; Nayak, M.K. Significance of activation energy, bio-convection and magnetohydrodynamic in flow of third grade fluid (non-Newtonian) towards stretched surface: A Buongiorno model analysis. Int. Commun. Heat Mass Transf. 2020, 118, 104893. [CrossRef]

21. Wager, H. On the effect of gravity upon the movements and aggregation of Euglena Viridis, Ehrb., and other micro-organisms Philos. Trans. R. Soc. Lond. B 1911, 201, 333-390.

22. Platt, J.R. "Bioconvection pattern" in cultures of the free-swimming organism. Science 1961, 133, 1766-1767. [CrossRef] [PubMed]

23. Kuznetsov, A. Bio-thermal convection induced by two different species of microorganisms. Int. Commun. Heat Mass Transf. 2011, 38, 548-553. [CrossRef]

24. Zohra, F.T.; Uddin, M.J.; Basir, F.; Ismail, A.I.M. Magnetohydrodynamic bio-nano-convective slip flow with Stefan blowing effects over a rotating disc. Proc. Inst. Mech. Eng. Part N J. Nanomater. Nanoeng. Nanosyst. 2019, 234, 83-97. [CrossRef]

25. Zhang, T.; Khan, S.U.; Imran, M.; Tlili, I.; Waqas, H.; Ali, N. Activation energy and thermal radiation aspects in bioconvection flow of rate-type nanoparticles configured by a stretching/shrinking disk. J. Energy Resour. Technol. 2020, 142, 1-19. [CrossRef]

26. Kotha, G.; Kolipaula, V.R.; Rao, M.V.S.; Penki, S.; Chamkha, A.J. Internal heat generation on bioconvection of an MHD nanofluid flow due to gyrotactic microorganisms. Eur. Phys. J. Plus 2020, 135, 1-19. [CrossRef]

27. Siddiq, M.K.; Ashraf, M. Bioconvection of micropolar nanofluid with modified Cattaneo-Christov theories. Adv. Mech. Eng. 2020, 12. [CrossRef]

28. Kumaraswamy Naidu, K.; Harish Babu, D.; Harinath Reddy, S.; Satya Narayana, P.V. Radiation and partial slip effects on MHD jeffrey nanofluid containing gyrotactic microorganisms over a stretching surface. J. Therm. Sci. Eng. Appl. 2020, 1-28. [CrossRef] 
29. Abdelmalek, Z.; Ullah Khan, S.; Waqas, H.; ANabwey, H.; Tlili, I. Utilization of second-order slip, activation energy, and viscous dissipation consequences in the thermally developed flow of third-grade nanofluid with gyrotactic microorganisms. Symmetry 2020, 12, 309. [CrossRef]

30. Abdelmalek, Z.; Khan, S.U.; Waqas, H.; Riaz, A.; Khan, I.A.; Tlili, I. A mathematical model for bioconvection flow of Williamson nanofluid over a stretching cylinder featuring variable thermal conductivity, activation energy, and second-order slip. J. Therm. Anal. Calorim. 2020, 1-13. [CrossRef]

31. Waqas, H.; Imran, M.; Muhammad, T.; Sait, S.M.; Ellahi, R. On bio-convection thermal radiation in Dar-cy-Forchheimer flow of nanofluid with gyrotactic motile microorganism under Wu's slip over-stretching cylinder/plate. In-ternational Journal of Numerical Methods for Heat \& Fluid Flow.tion and Brownian Motion. Mach. Learn. Res. 2020, 4, 51.

32. Wang, Y.; Waqas, H.; Tahir, M.; Imran, M.; Jung, C.Y. Effective prandtl aspects on bio-convective thermally developed magnetized tangent hyperbolic nanoliquid with gyrotactic microorganisms and second-order velocity slip. IEEE Access 2019, 7, 130008-130023. [CrossRef]

33. Li, Y.; Waqas, H.; Imran, M.; Farooq, U.; Mallawi, F.; Tlili, I. A Numerical exploration of modified second-grade nanofluid with motile microorganisms, thermal radiation, and Wu's slip. Symmetry 2020, 12, 393. [CrossRef]

34. Mahdy, A.; Nabwey, H.A. Microorganisms time-mixed convection nanofluid flow by the stagnation domain of an impulsively rotating sphere due to Newtonian heating. Results Phys. 2020, 103347. [CrossRef]

35. Khan, S.U.; Waqas, H.; Muhammad, T.; Imran, M.; Ullah, M.Z. Significance of activation energy and Wu's slip features in Cross nanofluid with motile microorganisms. Commun. Theor. Phys. 2020, 72, 105001. [CrossRef]

36. Ansari, M.S.; Otegbeye, O.; Trivedi, M.; Goqo, S.P. Magnetohydrodynamic bio-convective casson nanofluid flow: A numerical simulation by paired quasilinearisation. J. Appl. Comput. Mech. 2020. [CrossRef] 